\title{
Delayed Graft Function Diagnostic Criteria Name
}

National Cancer Institute

\section{Source}

National Cancer Institute. Delayed Graft Function Diagnostic Criteria Name. NCI

Thesaurus. Code C135514.

The name of a standard criterion from which a judgment concerning an occurrence of a delayed graft function (DGF) can be established. 